\title{
Problems of modelling the bond reinforcement in concrete
}

\author{
Ashot Tamrazyan* \\ Moscow State University of Civil Engineering, 129377, Moscow, Russia
}

\begin{abstract}
Traditional design research typically focuses on the design and construction of new structures, buildings and structures. A large proportion of existing concrete structures have wear problems. The longitudinal shear stress created by a load in reinforced concrete at the boundaries of concrete and reinforcement is considered. The parameters of numerous variables affecting this relationship are given, including the strength and cover of concrete, the type of reinforcement, the use of transverse reinforcement, the state of the reinforcement surface, the length of the anchorage, the stress state in the reinforcement, loading, and environmental influences. An empirical model obtained by the best comparison with test results is presented. The results of the mutual influence between loading and corrosion of reinforcing steel are presented. Research results show that loss of bond caused by structural failure becomes more critical compared to other types of failure as the life of the structure increases.
\end{abstract}

\section{Introduction}

The study of existing concrete structures includes various areas, such as: the mechanism of corrosion processes, models of adhesion of reinforcement to concrete, verification of calculation methods, cost estimation and analysis. For any concrete structure, a certain degree of deterioration can be tolerated because the structure is usually designed for high safety requirements, however, as maintenance progresses, the reliability of the structure decreases as deterioration begins.

The main task in this case consists in modeling and assessing the adhesion of reinforcement to concrete under various operating conditions [1-7].

The stress generated by the load in reinforced concrete is the longitudinal shear stress at the interfaces between concrete and reinforcement. This can lead to relative movement between concrete and reinforcement along its length. The ability to resist this movement is the adhesion force.

The bond strength of reinforcement and concrete is influenced by many factors. Strength of concrete and steel, bar diameter, concrete cover thickness, embedment length, rib geometry, bar spacing, clamps, temperature and corrosion are just a few of these factors. Influence of strength and composition of concrete

${ }^{*}$ Corresponding author: tamrazian@mail.ru 
The adhesion performance is influenced not only by the strength, but also by the composition and consistency of the concrete mix (for example, presence of cement, water, etc.).

The bonding properties are strongly influenced by the classification of aggregates and the consistency of the fresh concrete mixture. The harder the consistency of the mixture, the higher the adhesive power.

There is general agreement that the strength of concrete has a significant influence on adhesion behavior. When considering the effect of concrete strength on the distribution of bond stress along the length of the anchorage, it was found that, in specimens with eccentric extension, the place of maximum bond stress for the same force in the rods moved closer to the loaded end as the concrete strength increased. This indicates less slip when using harder concrete.

Compressive strength is considered a key parameter in adhesion behavior, sine force is transmitted through adhesion, and failure can occur as a result of tensile and shear splitting of the concrete. The slope of the bond stress distribution in concrete with higher strength varies significantly along the length of the joint compared to lower strength concrete.

The properties of concrete, both in tension and in compression, contribute to the development of bond stresses, micro cracks are controlled by tensile resistance. The compressive strength of concrete $\left(f_{c}\right)$, which was less than $69 \mathrm{MPa}$, showed a close relationship with the tensile and shear strength of concrete.

In [8], based on the results of tensile tests with concrete strength in the range from 16 to $50 \mathrm{MPa}$, it was noted that for the sliding range from 0.01 to $1 \mathrm{~mm}$, the bond stress is proportional to the compressive strength of concrete. However, for very small slip less than $0.01 \mathrm{~mm}$ and for high slip greater than $1 \mathrm{~mm}$, the effect of the compressive strength of the concrete is less important and is proportional to $2 / 3$ of the concrete strength. It was noted in [9] that bond stresses are proportional to the square root of concrete strength, based on the results of pull-off adhesion tests to a shear of $0.25 \mathrm{~mm}$ with concrete strengths of 40,80 and $120 \mathrm{MPa}$.

Studies on the adhesion behavior of more brittle and high strength concrete are limited, and there seems to be no consensus on its effect on the adhesion between steel and concrete. More experimental research is needed to assess its effect on adhesion performance.

\section{The effect of the protective concrete cover.}

The bond strength increases with the thickness of the protective concrete cover. The protective cover of concrete and the distance between the reinforcement significantly affect the type of bond failure. Tensile fracture, splitting failure occurs with a small protective concrete cover, and the pull-off strength will be higher for greater thickness.

\section{Influence of corrosion on adhesion}

As the steel bar corrodes, the increased volume of corrosion products leads to "bursting" pressure, which causes longitudinal splitting cracks in the specimens. Besides, the crack width increasing with increasing corrosion rates. This leads to a failure of adhesion and friction at the steel-concrete interface, except for low levels of corrosion where there is no longitudinal cracking and the corrosion products have a positive effect on improving the adhesion characteristics at the interface. At higher corrosion levels, steel rods show 
localized pitting corrosion and loss of some ribs along the length of the rod, thereby weakening the mechanism for transferring mechanical bond between the ribs and the concrete. A study of the number and intensity of transverse cracks shows that as the level of corrosion increases, the distance between transverse cracks also increases, reflecting the deterioration of adhesion characteristics at the steel-concrete interface [10].

Adhesion is a chemical bond that is created at the interface between reinforcement and concrete. For relatively light loads, the main resistance mechanism is chemical adhesion. However, as the load increases, the chemical adhesion along the rod surface is rapidly lost. In fact, it was assumed that adhesion could be compromised by the action of working loads or by concrete shrinkage. Consequently, as the load increases, the strength of the adhesive bond is lost.

Adhesion strength is provided by three types of mechanisms: adhesion, friction and mechanical locking. Adhesion is the chemical and physical bond between cement stone and reinforcement.

Friction is caused by compressive stress, which can be caused by shrinkage of concrete, roughness of the sliding plane, jamming of cement stone particles, ribs of deformed rods; Poisson effect from longitudinal compressive stress due to transverse expansion of the reinforcement. Reinforcement ribs and concrete, cement stone and microscopically rough reinforcing surface intersect with each other at the joints of concrete and reinforcement. A small relative movement (sliding) between concrete and reinforcement will create a compressive force perpendicular to the surfaces, as shown in Figure 1.

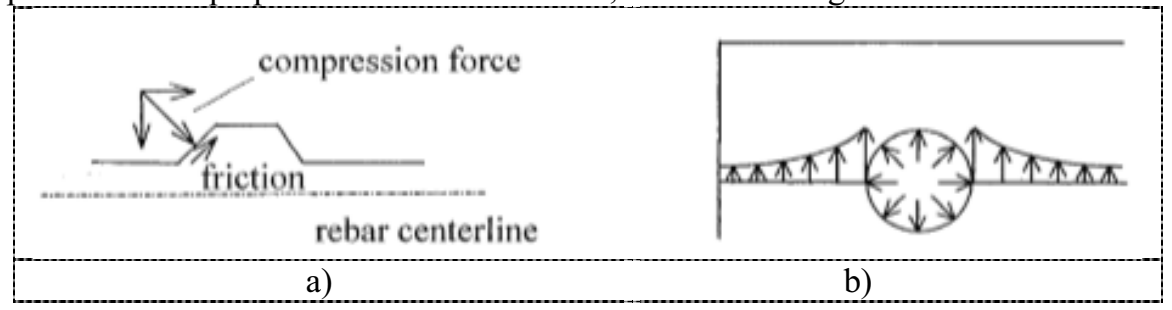

Fig. 1. Blocking adhesion forces. a) Forces on Rebar, b) Radial and splitting stresses in concrete.

This results in friction along the interfaces in proportion to the compressive force. The longitudinal component of friction resists relative motion, in which greater resistance is provided by the equilibrium force of the longitudinal component of the compressive force. This resistance is called blockage.

The ribs of the deformed bars mainly contribute to mechanical blocking. Another small part is the microscopically rough surface of the steel reinforcement. On the other hand, the balancing force of the transverse component induces radial compressive stress in the concrete.

When there is no slip, bond strength is mainly provided by adhesion, but adhesion will be quickly lost even if there is little slip or reduction in the diameter of the reinforcement in tension due to Poisson's effect. Bond tension is transmitted by friction and mechanical interlocking. As slip increases, mechanical interlocking becomes the primary bond mechanism.

For smooth reinforcement, the bond strength is mainly provided by adhesion and friction; therefore, the bond strength of such reinforcement is much lower than that of periodic profile reinforcement. In addition, the bond strength in the compressed zone is generally higher than in the tension zone due to the lateral expansion of the reinforcement. 


\section{Main part}

\subsection{Stress connections}

As mentioned earlier, the bond stress is the longitudinal shear stress caused by the loading at the interfaces between concrete and reinforcement. Considering the diagram of a small section of reinforcement embedded in a beam and subjected to tension or compression (see figure 2), the corresponding average bond stress can be expressed as:

$$
\tau_{\text {ave }}=\Delta P /\left(l_{p} \Delta x\right)=\left(A_{s} \Delta \sigma_{s}\right) /\left(l_{p} \Delta x\right)=d_{s} \Delta \sigma_{s} /(4 \Delta x)
$$

where $A_{s}$-is the cross-sectional area of the reinforcement; $\Delta \sigma_{s}$ - change in stress in the part of the reinforcement; $l_{p}$ - the perimeter of the cross-section of the reinforcement; $\Delta_{x}$ length of part of the reinforcement; $d_{s}$ - reinforcement diameter.

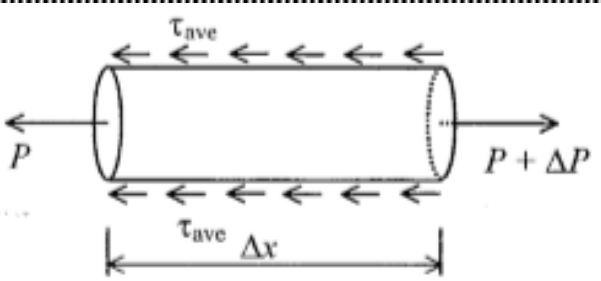

Fig. 2. Reinforcement segment subjected to tension and medium stress connection

Having established the length of the section approaching zero, that is $\Delta \sigma_{s} \rightarrow d \sigma_{s}$ and $\Delta_{x}$ $\rightarrow d_{x}$, the expression [11] is obtained:

$$
\left.\tau_{b}=1 / 4 d_{s} d \Delta \sigma_{s}\right) / d x
$$

You can see that the joint stress is proportional to the diameter of the reinforcement and the stress gradient in the reinforcement. Figure 3 shows a diagram of a portion of a reinforced beam in a pure bend zone.

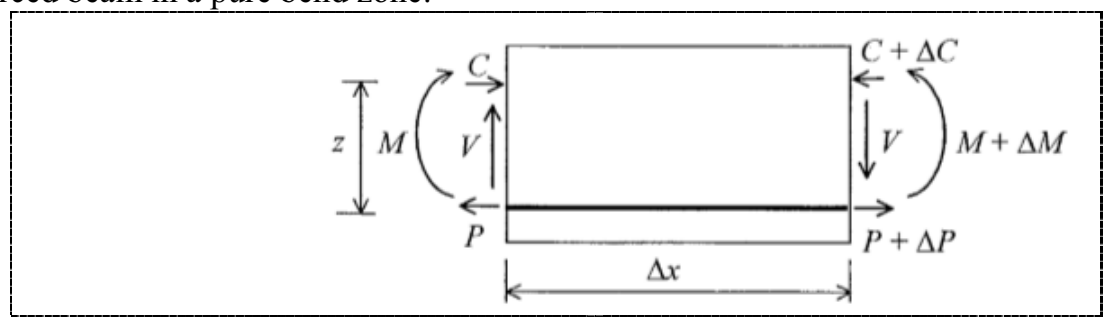

Fig. 3. A fragment of a beam in conditions of pure bending

Ignoring the tensile forces exerted by concrete, the corresponding change in the axial force in the reinforcement can be written as:

$$
\Delta P=\Delta M / z
$$

where $z$ - shoulder of the moment.

By substituting the above equation in (1), the average adhesion stress can be obtained:

$$
\tau_{\text {ave }}=\Delta P /\left(l_{p} \Delta x\right)=\Delta M /\left(\pi d_{s} z \Delta x\right)=V /\left(\pi d_{s} z\right)
$$

where $V$ - is the shear force. 
It can be concluded that the bond stress in the reinforcement is mainly caused by the moment gradient, that is, the shear force.

If there is a crack on one side of a beam section (Fig. 4), additional axial forces in the reinforcement due to blocking must be taken into account [12].

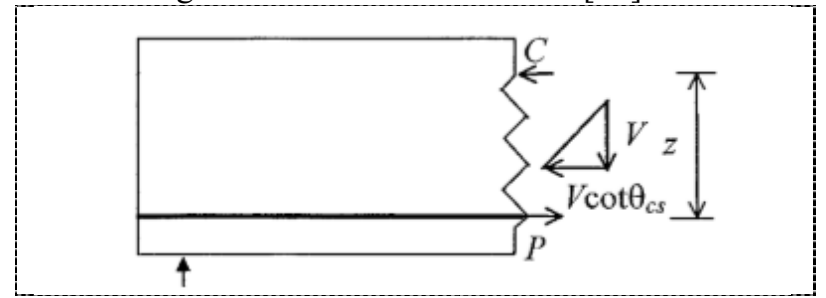

Fig. 4. Section of a beam with a crack

In this case, equation (3) should be changed:

$$
\Delta P=\Delta M / z+V \cot \theta_{c s} / 2
$$

where $\theta_{c s}$ - is the angle of inclination of the crack surface (Fig.4), this can be expressed using:

$$
\cot \theta_{c s}=V S_{s v} /\left(A_{s v} \sigma_{s v} z\right)
$$

where $A_{s v^{-}}$is the area of the transverse reinforcement (or stirrup), $\sigma_{s v}$ - is the corresponding stress, and $S_{S v}$-is the step of the stirrups.

Since the bond stress is the stress gradient in the reinforcement (2), the bond stress distribution can be easily plotted by knowing the stress distribution in the reinforcement. Figure 5 shows a typical tensile experiment as well as the distribution of bond stresses and stresses in reinforcement.

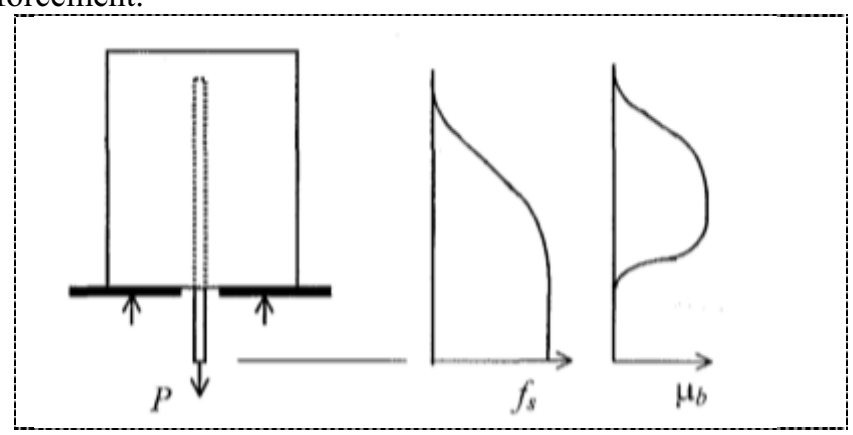

Fig. 5. Type tensile test and stress distribution in reinforcement and in connection

A bond break is defined when the bond resistance is lower than the shear force due to bond stress. Considering a structural member under increasing stress, with increasing bond stress due to the load, adhesion is lost with little slip. Then the bond stress is mainly transferred by friction for smooth reinforcement and friction, and mechanical blocking for reinforcement with a periodic profile. Mechanical blocking causes radial compressive stress in the concrete and this is balanced by a tensile ring in the concrete around the reinforcement. The peak tensile stress is at the concrete interface and decreases with increasing distance to the interface. If the tensile stress at the interface reaches the ultimate strength of the concrete, then microcracks are formed. With a further increase in load, cracks parallel to the reinforcement can expand and finally reach the concrete surface. As cracks develop, the bond strength decreases rapidly. 


\subsection{Bonding strength models}

Reinforcement in concrete has become a problematic topic, mainly due to complex mechanisms, numerous variables affecting communication, high uncertainty and the use of new materials [13]. According to research, there are a number of critical variables that influence connection behavior:

- strength and protective layer of concrete, which are mainly related to the holding capacity of concrete; the size of the reinforcement, the larger the diameter, the higher the bond strength and the lower the bond stress;

- reinforcement type: steel or non-metallic reinforcement, for example, plastic fiber, smooth or ribbed. As a rule, the bond strength of a smooth reinforcement is much less than that of a periodic profile due to the absence of mechanical blocking;

- use of transverse reinforcement. This can improve the retention of the concrete;

- surface condition of the reinforcement: clean, oiled, rusty, epoxy coated or not; the use of an epoxy coating results in a decrease in bond strength, typically the range of bond strength ratios for uncoated and coated reinforcement is 1.0 to 1.35 ;

- length of reinforcement anchorage;

- stress state in reinforcement: tension or compression;

- load: static, multiple or impact, etc.;

- environmental influences: temperature, reinforcement corrosion, etc.

Existing research continues to rely on empirical models obtained by best matching with test results. Of these empirical models, the most accepted is the model proposed by [14]:

$$
\tau_{b}=\left[0,1+0,25 a / d_{s}+4,15 d_{s} / l_{s}+A_{s v} \sigma_{y t} /\left(41,52 S_{s v} d_{s}\right)\right] \sqrt{R_{b}}
$$

where $\tau_{b}$ - is the adhesion strength in $\mathrm{MPa} ; a$ - concrete cover in $\mathrm{m} ; d_{s}$ - rod diameter in $\mathrm{m} ; l_{s}$ - anchoring length in $\mathrm{m} ; A_{s v}$ - area of transverse reinforcement in $\mathrm{m} 2 ; \sigma_{y t}$ - yield strength of transverse reinforcement in $\mathrm{MPa} ; S_{S v}$ - step of stirrup in $\mathrm{m} ; R_{b}$-is the specified compressive strength of concrete in $\mathrm{MPa}$.

This model takes into account the effects of diameter, concrete retention (value $0.25 \mathrm{a} / d_{s}$ ), anchorage length, shear reinforcement and concrete tensile strength, which is proportional to the square root of the specified compressive strength of concrete.

Model [14] is one of the most frequently referenced models and has been chosen as the basis for the ACI adhesion standards over the past thirty years.

Considering the reinforcement in a beam with a length, the corresponding average bond stress can be expressed using equation (8):

$$
\tau_{\text {ave }}=\Delta P /\left(l_{p} \Delta x\right)=\left(A_{s} \Delta \sigma_{s}\right) /\left(\pi d_{s} l_{s}\right)
$$

Since the stress in the reinforcement at the end of the anchorage is zero, the above equation can be modified as follows:

$$
\pi \tau_{\text {ave }} d_{s} l_{s}=A_{s} \sigma_{s}
$$

where $\sigma_{s}$-is the stress in steel in the selected cross section.

By replacing the average bond stress with bond strength, the left term of the above equation becomes the bond resistance of the reinforcement:

$$
T_{b}=\pi \tau_{b} d_{s} l_{s}
$$

It should be noted that the longer the embedment length, the greater the bond resistance will be. To ensure that the bond resistance is not completely lost before the reinforcement emerges, the code introduces the concept of the calculated length $l_{d}$ - this is the shortest 
embedment length of the reinforcement exposed to the yield force without loss of adhesion. Using equations (9), (10) and taking into account the yield stress, we have:

$$
l_{d}=\left(A_{s} \sigma_{y}\right) /\left(\pi \tau_{b} d_{s}\right)=\left(\sigma_{y} d_{s}\right) /\left(4 \tau_{b}\right)
$$

where $\sigma_{y}$-is the yield strength of the reinforcement.

By applying the bond strength model, the corresponding length can be obtained in terms of the critical variables affecting the bond. For design purposes, the codes for adhesion resistance equations are simplified and simple factors are taken to account for the influence of critical variables such as rebar position, bar diameter, epoxy coating, rebar spacing, etc.

\subsection{Loss of adhesion due to corrosion of steel}

The code provides a simple way of verifying adhesion requirements only for the design of new structures subjected to normal loads. Ideal linkage is usually assumed for evaluating in-service structures. As mentioned earlier, the ideal adhesion assumption is an easy way to model a structure, but gives unrealistic results, especially for structures exposed to corrosive attack or unexpected loading. Recently, both experimental and theoretical studies have shown that a decrease in bond strength due to deterioration of reinforcement has a significant effect on the bearing capacity.

In [15], the mutual influence between load and corrosion of reinforcing steel was studied by experimenting with 10 identical beams subjected to different loads and corrosion conditions. The test results show that beams without corrosion or mild corrosion were destroyed due to shear failure, whereas beams that lost more than $3.2 \%$ of the weight loss of reinforcement failed due to bond failure or a combination of shear and bond failure. In another independent experiment with beams subjected to simulated localized pitting [16], it was found that the deterioration observed in corroded specimens, such as significant loss of flexural stiffness and asymmetric behavior, can only be attributed to a decrease in reinforcement cross-section and loss of bond strength.

In independent but similar analytical studies [17] and [18], numerical simulations were performed, taking into account the reduction in the cross-section of the reinforcement and the loss of bond due to concrete delamination. In [17], the spatial variation and degradation of variables along the length of the structure were considered by introducing correlation functions. This differs from [18], which studied the change in wear between different rods in the same section. The results of both studies indicate that the loss of bond caused by structural failure is likely to become more and more critical compared to other types of failure as the life of the structure increases and the failure process continues. This is consistent with experimental results [15]. In addition, the results of the analysis also show that the probability of bond failure slowly increases during the initial period of time, after which a sudden change occurs after the concrete delamination. This is due to an unknown loss of adhesion prior to delamination of the concrete.

\section{Conclusions}

Research shows that the assumption of a perfect relationship can lead to unreliable results. A rational assessment of the aging of a reinforced concrete structure requires models of bond failure and spatial change in structure variables and wear, as well as an appropriate analysis method based on reliability.

\section{References}


1. A.G. Tamrazyan, D. Popov, Reduce of bearing strength of the bent reinforced concrete elements on a sloping section with the corrosive damage of transversal armature, Applied Matec Web of Conferences, 117, 00162 (2017).

2. A.G. Tamrazyan, The assessment of reliability of punching reinforced concrete beamless slabs under the influence of a concentrated force at high temperatures, Procedia Engineering, 153, 715-720 (2016).

3. A.G. Tamrazyan, L.A. Avestisyan, Experimental and theoretical study of reinforced concrete elements under different characteristics of loading at high temperatures, Procedia Engineering, 153, 721-725 (2016).

4. A.G. Tamrazyan, Reduce the impact of dynamic strength of concrete under fire conditions on bearing capacity of reinforced concrete columns, Applied Mechanics and Materials, 475-476, 1563-1566 (2014).

5. A.G. Tamrazyan, L.A. Avestisyan, Behavior of compressed reinforced concrete columns under thermodynamic influences taking into account increased concrete deformability, IOP Conference Series: Materials Science and Engineering, 365 (5) 52034 (2018).

6. O.V. Kabantsev, A.G. Tamrazyan, Allowing for changes in the calculated scheme during the analysis of structural behavior, Magazine of civil engineering, 49 (5),15-26 (2014).

7. A.G. Tamrazyan, L.A. Avestisyan, Estimation of load bearing capacity of eccentrically compressed reinforced concrete elements under dynamic loading in fire conditions, Applied mechanics and materials, 638-640, 62-65 (2014).

8. P. Kumar Mehta, Concrete Structure, Properties, and Materials, Prentice- Hall, Inc., Englewood Cliffs, N.J. 07632 (1993)

9. R.A. Treece, and J.O. Jirsa, Bond Strength of Epoxy-CoatedReinforcing Bars, ACI Materials Journal, 86 (2), 167-174 (1989)

10. L. Amleh, M.S. Mirza, and J. Mirza, Effect of Fly Ash Concrete Mix on Corrosion of Steel Reinforcement, Proceedings of the Annual Conference of the Canadian Society for Civil Engineering, Halifax, Nova Scotia, June10-13, pp. 783-792 (1998)

11. MacGregor, Reinforced concrete mechanics and design Prentice Hall (1997).

12. P.E. Regan, Shear Concrete Society Current Practice Sheet Concrete, 105, 25-26 (1985).

13. R. Tepfers, Bond of FPR reinforcement in concrete: A state-of the art paper Bond and Development of Reinforcement, ACI SP, 180 (1998).

14. C.O. Orangun, J.O. Jirsa, J.E. Breen, A reevaluation of Test Data on Development length and Splices, Journal of ACI, 74 (3) (1997).

15. S. Yoon, Interaction between loading, corrosion, serviceability of reinforced concrete, ACI materials Journal, 97 (6), 637-64 (2000).

16. A. Castel, R. Francois, G. Arliguie, Mechanical behavior of corroded reinforced concrete beams-part 2: bond and notch effect, Material Structure, 233, 539-544 (2000).

17. G. Sterritt, M.K. Chryssanthopoulos, Probabilistic limit state modeling of deteriorating $R C$ bridge using a spatial approach, Proceedings of International Conference on Current and Future Trends in Bridge DesignConstruction and Maintenance, 518-528 (1999).

18. V. Sarveswaran, M.B. Roberts, J.A. Ward, Reliability assessment of deteriorating 
reinforced concrete beams, Proceedings of Institution of Civil Engineering: Structures \& Buildings, 140 239-247 (2000). 